\title{
Polymeric Bearings as a new base isolation system suitable for mitigating machine-induced vibrations
}

\author{
Tomasz Falborski ${ }^{1,{ }^{*}}$ and Robert Jankowski ${ }^{1}$ \\ ${ }^{1}$ Faculty of Civil and Environmental Engineering, Gdansk University of Technology, 11/12 \\ Narutowicza St., 80-233 Gdańsk, Poland
}

\begin{abstract}
The present paper summarizes the preliminary results of the experimental shaking table investigation conducted in order to verify the effectiveness of a new base isolation system consisting of Polymeric Bearings in reducing strong horizontal machine-induced vibrations. Polymeric Bearing considered in the present study is a prototype base isolation system, which was constructed with the use of a specially prepared flexible polymer with improved damping properties. Dynamic oscillatory tests, during which a concrete base slab supported by four Polymeric Bearings was subjected to horizonal sinusoidal excitations characterized by different frequencies and amplitudes, were conducted in order to determine the damping properties of Polymeric Bearings and their effectiveness in mitigating structural vibrations. Equivalent damping ratios for every excitation frequency considered were determined using the experimentally obtained hysteresis loops. Final conclusions are presented and the results discussed.
\end{abstract}

\section{Introduction and motivation}

Vibrations can be triggered by many different factors, such as earthquake-induced ground motions (see, for example, [1,2]), dynamic crowd loads (see, for example, [3]), or pounding effects (see, for example, [4-9]). Also, machines with rotating or oscillating parts, which are often installed in industrial facilities, may sometimes cause undesirable dynamic excitations that are transferred into the building structure (see, for example, [10-12]). Strong machineinducted vibrations are an issue of major concern as they may lead to deteriorating comfort of the occupants, interrupt work performance of other machines (specifically those of highsensitivity or high-precision), or even result in damage of structural members. Most importantly, if there is a need to make an industrial facility remain unfunctional due to any of these potential threats, a non-operating period may additionally cause far-reaching financial consequences.

Motivated by this discussion, the present paper reports the preliminary results of the experimental shaking table investigation designed to verify the effectiveness of a new base

\footnotetext{
* Corresponding author: tomfalbo@.pg.gda.pl
} 
isolation system consisting of Polymeric Bearings (PBs) in reducing horizontal machineinduced vibrations. In order to determine the damping properties of Polymeric Bearings in mitigating structural vibrations, dynamic oscillatory tests, during which a concrete base slab supported by four Polymeric Bearings was subjected to horizonal sinusoidal excitations characterized by different frequencies and amplitudes, were conducted.

\section{Polymeric Bearings}

PB considered in the present study is a prototype base isolation system, which was constructed with the use of a specially prepared flexible polyurethane-based material characterized by improved damping properties. PB consists of a polymer cylinder $(28 \mathrm{~mm}$ in diameter and $28 \mathrm{~mm}$ high) with a centrally located hole (14 $\mathrm{mm}$ in diameter), into which a pin-ended steel core $(6 \mathrm{~mm}$ in diameter) was inserted. The total height of this device, including two steel plates (30 $\mathrm{mm}$ in diameter and $15 \mathrm{~mm}$ high) mounted at both ends of the polymer cylinder, is $58 \mathrm{~mm}$. In this base isolation system, the steel core sustains vertical forces, whereas the polymer cylinder is subjected only to shearing. This solution makedly increases vertical stiffness and also prevents from an undesirable bulging of the bearing.

More detailed description of PBs, polymer properties (determined through static tension and compression tests, Dynamic Mechanical Analysis, etc.), and shaking table investigation results, which confirmed very high effectiveness of PBs in reducing earthquake-induced vibrations of two steel structure models (representing low-rise and medium-rise buildings), were already published (see $[13,14]$ ). It should also be noted that a full-scale PB was patented in Polish Patent Office in 2017.

The material used to make PBs was also used to construct special dampers to mitigate human-induced vibrations of steel grandstand during sports events (see [15-17]), and suppress pounding effects between adjacent buildings under strong ground motions (see [18]).

\section{Dynamic oscillatory tests}

Dynamic oscillatory tests were conducted in order to determine the damping properties of the PBs under harmonic excitations. This experimental investigation was performed with the use of the shaking table platform located at Gdansk University of Technology (GUT), Poland. In order to evaluate the damping potential, four PBs, supporting a concrete slab with dimensions of $50 \mathrm{~cm} \times 50 \mathrm{~cm} \times 7 \mathrm{~cm}$ ), were mounted on the shaking table platform and subjected to dynamic sinusoidal excitations. The experimental testing was carried out at three excitation frequencies $(1,2$, and $5 \mathrm{~Hz}$ ) for different shear strain levels. The response of the system was measured using a laser displacement sensor and an uniaxial accelerometer, as indicated by Figure 1. The lateral force was obtained by multiplying the total mass of the system and the recorded acceleration. As an example, the experimentally obtained hysteresis loops at excitation frequency of $1 \mathrm{~Hz}$ are presented in Figure 2. In accordance to [19], for every excitation frequency considered in this study, an equivalent damping ratios were determined and briefly summarized in Table 1.

Results obtained confirmed profound energy-dissipation potential of PBs as the equivalent damping ratios range from $20 \div 49 \%$. It can also be observed that the dynamic behaviour of PBs is strongly dependent on the excitation frequency. The higher the excitation frequency, the higher the value of the equivalent damping ratio. Also, PBs exhibit higher stiffness at lower shear strain levels. As the shear deflection increases, the slope of the hysteresis loop decreases. 


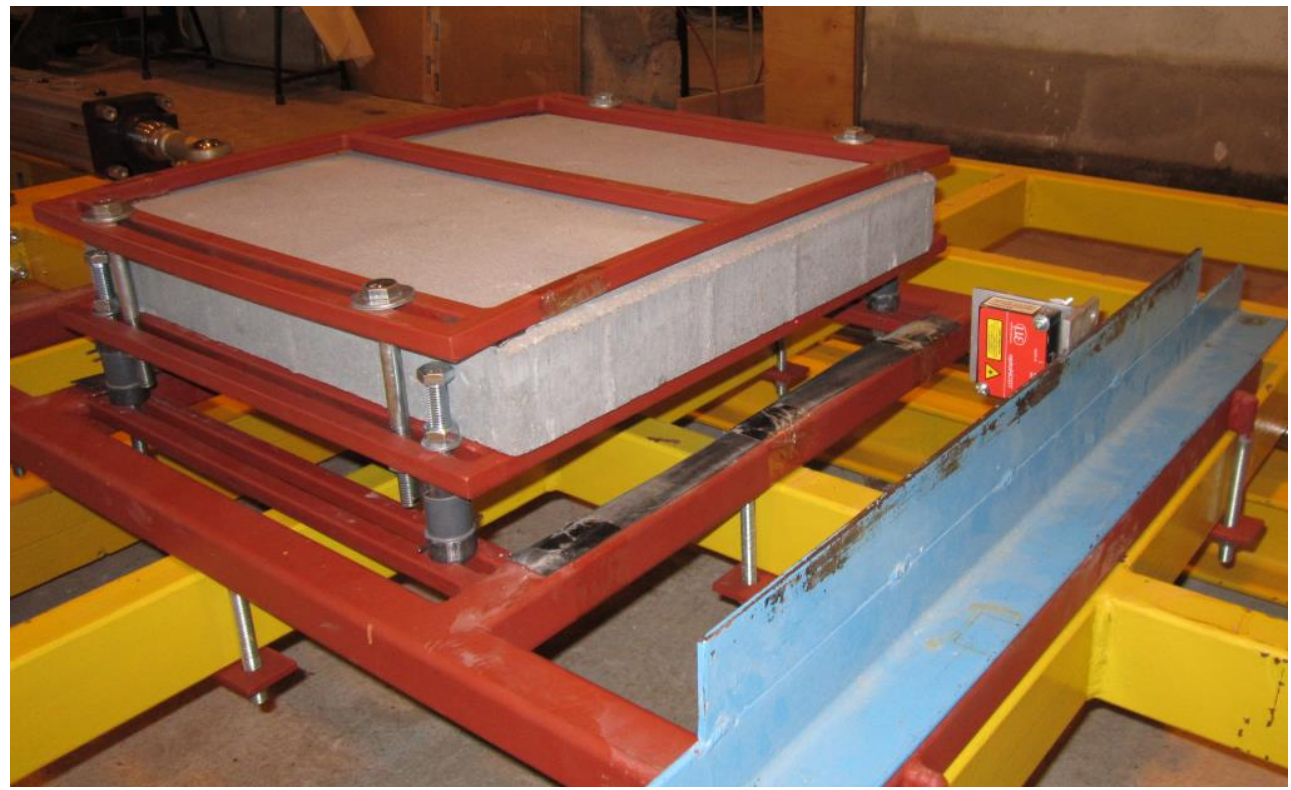

Figure 1. Concrete base slab supported by four PBs during dynamic oscillatory tests.

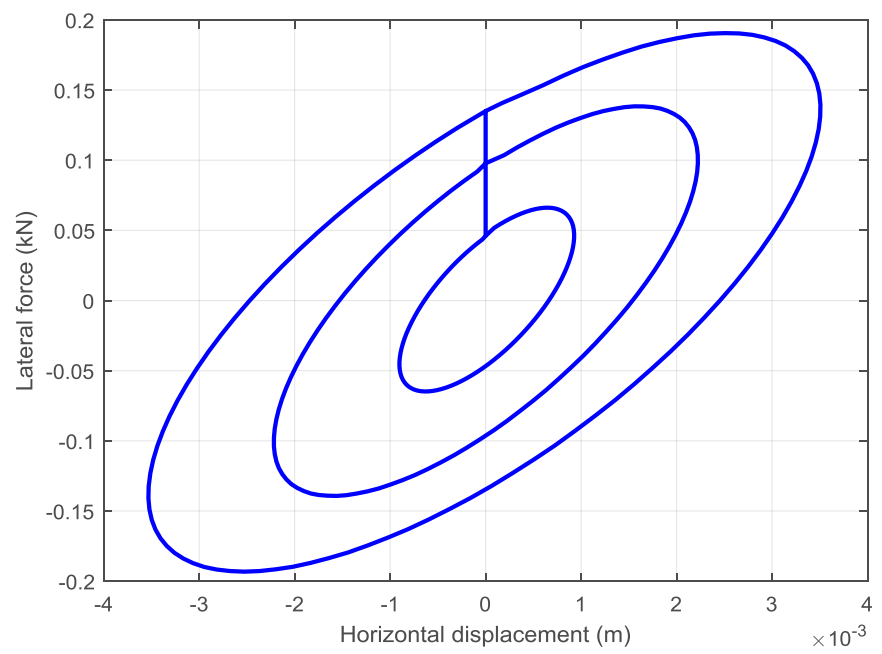

Figure 2. Hysteresis loops obtained for excitation frequency of $1 \mathrm{~Hz}$.

Table 1. Damping ratios of PBs for different excitation frequencies.

\begin{tabular}{|c|c|}
\hline $\begin{array}{c}\text { Excitation } \\
\text { frequency }\end{array}$ & $\begin{array}{c}\text { Damping } \\
\text { ratio }\end{array}$ \\
\hline $1 \mathrm{~Hz}$ & $49.5 \%$ \\
\hline $2 \mathrm{~Hz}$ & $30.5 \%$ \\
\hline $5 \mathrm{~Hz}$ & $20.4 \%$ \\
\hline
\end{tabular}




\section{Conclusions}

The results of the dynamic oscillatory tests explicitly show that the base isolation system consisting of PBs exhibits pronounced hysteretic behaviour under cyclic loading which confirms its high energy dissipation properties. Base isolation technique is effective even if the system is linear and undamped. A certain level of damping, however, is profoundly beneficial in further reducing lateral forces and deformation in the isolation system. Moreover, experimentally obtained hysteresis loops, which are presented in Figure 1, indicate that PBs exhibit higher stiffness at lower shear strain levels. It can be seen that with increasing shear deflection, the slope of the hysteresis loop decreases. Additionally, the obtained results clearly demonstrate that the higher the excitation frequency, the lower the value of equivalent damping ratio, as indicated by Table 1 . The cyclic loading tests indicate that the damping ratio provided by PBs ranges from $20 \div 49 \%$, while for the most commonly used isolators the damping ratio is approximately $10 \div 20 \%$.

The experimental testing confirmed relatively high potential of the PBs to mitigate lateral forces and to suppress machine-induced structural vibrations.

Nevertheless, further development of this base isolation system is needed to fully verify its applicability to mitigate strong machine-induced vibrations. Further studies will cover experimental investigation with the use of machines with rotating parts to generate lateral vibrations.

\section{References}

[1] T. Falborski, R. Jankowski, Procedia Engineering, 172, 277-283 (2017)

[2] M. Ebrahimian, M.I. Todorovska, T. Falborski, Journal of Structural Engineering, 143(4), Paper np. 04016217 (2017)

[3] N. Lasowicz, R. Jankowski, Civil and Environmental Engineering Reports, 16(1), 119128 (2015)

[4] R. Jankowski, S. Mahmoud, Earthquake-Induced Structural Pounding (Springer, Cham, Switzerland, 2015)

[5] H. Elwardany, A. Seleemah, R. Jankowski, Engineering Structures, 144, 139-150 (2017)

[6] R. Jankowski, S. Mahmoud, Bulletin of Earthquake Engineering, 14, 3075-3097 (2016)

[7] H. Naderpour, R. C. Barros, S.M. Khatami, R. Jankowski, Shock and Vibration, 2016, article ID 1504783 (2016)

[8] R. Jankowski, Journal of Earthquake and Tsunami, 9, Paper no. 1550012 (2015)

[9] R. Jankowski, Key Engineering Materials, 293-294, 711-718 (2005)

[10] J.M. Vance, F.Y. Zeidan, B. Murphy Machinery Vibration and Rotordynamics (Wiley, New Jersey, USA, 2010)

[11] O. Matsushita, M. Tanaka, H. Kanki, M. Kobayashi, P. Keogh. Vibrations of Rotating Machinery (Springer, Cham, Switzerland, 2017)

[12] G. Genta, Vibration of Structures and Machines (Springer, Cham, Switzerland, 1999)

[13] T. Falborski, R. Jankowski, A. Kwiecień, Key Engineering Materials, 488, 347-350 (2012)

[14] T. Falborski, R. Jankowski, Applied Sciences, 7(8), 808 (2017)

[15] N. Lasowicz, R. Jankowski, Key Engineering Materials, 713, 171-174 (2016)

[16]N. Lasowicz, A. Kwiecień, R. Jankowski, Journal of Physics: Conference Series, 628, 1-7 (2015)

[17] N. Lasowicz, A. Kwiecień, R. Jankowski, Key Engineering Materials, 624, 478-485 (2015) 
[18] B. Sołtysik, T. Falborski, R. Jankowski, Procedia Engineering, 199, 278-283 (2017)

[19]R. Jankowski, Bulletin of Earthquake Engineering, 1(3), 397-403 (2003) 